\title{
SUPLEMENTAÇÃO EDUCACIONAL PARA ALUNOS DOTADOS E TALENTOSOS DO PROGRAMA DECOLAR
}

\author{
SUPLEMENTACIÓN EDUCACIONAL PARA ALUMNOS DOTADOS Y \\ TALENTOSOS DEL PROGRAMA DECOLAR
}

\author{
EDUCATIONAL SUPPLEMENTATION FOR GIFTED AND TALENTED \\ STUDENTS AT PROGRAMA DECOLAR
}

\author{
Luciane Mirella de Souza OLIVEIRA ${ }^{1}$ \\ Rosemeire de Araújo RANGNI ${ }^{2}$
}

RESUMO: O presente artigo propôs analisar as políticas públicas educacionais na oferta de suplementação educacional pelo Programa Decolar da rede de ensino municipal de São José dos Campos, interior de São Paulo, Brasil, no período de 2011 a 2013. A pesquisa de natureza exploratória buscou dados documentais no referido Programa. Concluiu-se que o atendimento educacional especializado em caráter suplementar ofertado foi realizado de acordo com as políticas públicas educacionais no período pesquisado e apontou algumas tendências na oferta da suplementação, como o aumento no número de atividades de um semestre para o outro e a influência do ambiente nos interesses manifestados pelos alunos.

PALAVRAS-CHAVE: Suplementação educacional. Dotação. Talento.

RESUMEN: El presente artículo propone analizar las políticas públicas educacionales para el ofrecimiento de suplementación educacional del Programa Decolar en la red de enseñanza de la ciudad de São José dos Campos, en interior de São Paulo, Brasil, en 2011 a 2013. La investigación con naturaleza de exploración buscó indicación documentales del Programa. Se concluyó que el atendimiento educacional especializado, de manera suplementar ofrecido, fue realizado de acuerdo con las políticas educacionales en la época investigada y apunto algunas tendencias en la oferta de suplementación, como el aumento del número de actividades de un semestre para otro y la influencia del ambiente en los intereses manifestados por los alumnos.

PALABRAS-CLAVE: Suplementación educacional, dotación, talento.

ABSTRACT: The present paper proposed to analyze the educational supplementation offered by Programa Decolar in the municipal education system of São José dos Campos, countryside of São Paulo state, Brazil, in the period from 2011 to 2013. Exploratory research sought documents data from the referred program. It was

\footnotetext{
${ }^{1}$ Graduada em Letras (UNESP - Assis) e Pedagogia (UFSCar) e pós-graduada (lato sensu) em Educação Especial de Bem Dotados e Talentosos (UFLA). Bolsista PIBIC-CNPQ. profalucianemirella@gmail.com ${ }^{2}$ Professora Adjunta III no Curso de Licenciatura em Educação Especial e Pós - Graduação em Educação Especial (UFSCar). Departamento de Psicologia. rose.rangni@uol.com.br
} 
concluded that the educational specialized service in supplementary character offered by that system was carried out in accordance with the educational policy in the period researched, and pointed to some trends in the provision of supplementation, as the increase in the number of activities from one semester to the next, and the influence of the environment on the interests expressed by the students.

KEYWORDS: Educational supplementation. Giftedness. Talent.

\section{Introdução}

A Política Nacional da Educação Especial na Perspectiva da Educação Inclusiva (BRASIL, 2008), reiterada e atualizada pela Lei Diretrizes e Bases da Educação Nacional (BRASIL, 1996), considera a educação especial como modalidade de ensino e parte da proposta pedagógica da escola, definindo seu público-alvo os alunos com deficiência, transtornos globais do desenvolvimento e altas habilidades/superdotação.

A política acima citada conceitua os alunos com altas habilidades/superdotação sendo aqueles que:

demonstram potencial elevado em qualquer uma das seguintes áreas, isoladas ou combinadas: intelectual, acadêmica, liderança, psicomotricidade e artes. Também apresentam elevada criatividade, grande envolvimento na aprendizagem e realização de tarefas em áreas de seu interesse (BRASIL, 2008, p. 9).

Entretanto, conceitos e definições, assim como as terminologias utilizadas para definirem as pessoas com alto potencial, não possuem unanimidade. Gagné (2005) apresenta definições como dotação e talento $^{3}$, termos geralmente utilizados como sinônimos, como dois construtos diversos, diferenciando-os em seu Modelo Diferenciado de Dotação e Talento - DMGT 2.0 - como sendo:

Dotação: designa posse e uso de capacidade natural notável (chamada aptidão elevada ou dote) em pelo menos um domínio de capacidade, a um grau que coloco o indivíduo entre pelo menos os $10 \%$ superiores no grupo de pares etários.

Talento: designa notável superioridade em competências sistematicamente desenvolvidas (conhecimento e habilidades), em pelo menos um campo de atividade humana, a um grau que coloca o indivíduo entre pelo menos os $10 \%$ superiores no grupo de pares etários que são, ou já foram, ativos naquele campo ou áreas (GAGNÉ, 2005, p.33).

3 Neste trabalho adotaremos as terminologias “dotação e talento" proposto por Gagné (2008) e Guenther (2011), porém, manter-se-ão os termos utilizados por outros autores e textos oficiais. 
Assim, Gagné evidencia diferenças conceituais que passam a permear as reflexões acerca do trabalho educacional com os alunos dotados e talentosos, oferecendo fundamentação para a organização do trabalho pedagógico. Baseada nos conceitos pontuados por Gagné, Guenther (2012) explica que desenvolver talentos pode ser mais simples e obter resultados mais rápidos, mas propõe que a escola busque focar o desenvolvimento da dotação visto que esse pode surtir efeitos de longo prazo e ser mais útil à sociedade.

Além de diferenciar dotação de talento, Guenther (2011, p.40) explica que:

Capacidade natural não se manifesta como um bloco de atributos gerais, ao contrário, é definida e expressa dentro de Domínios diferenciados, (GAGNÉ, 2008), que podem ser rastreados a funções cerebrais (CLARK, 1984). Tais domínios sinalizam pelo menos quatro ou cinco áreas de potencial, expressas por canais de interesse, atividade e desempenho que estejam disponíveis no ambiente. (Grifos da autora)

A autora mencionada também explica que o domínio da inteligência pode expressar-se em forma de pensamento linear (verbal), o qual é mais comumente reconhecido no ambiente escolar ou pode expressar-se em forma de pensamento não linear (espaço-visual), mais dificilmente percebido no ambiente escolar por não ter começo, meio e fim. Quanto ao domínio da criatividade, ela afirma serem os alunos mais "fora dos padrões", entediados e críticos. Em relação ao domínio da capacidade socioemocional se expressa pela via da liderança ou das relações humanas. Os domínios de capacidade citados pela referida autora são: inteligência, criatividade, socioemocional, perceptual e física.

No tocante às políticas públicas para a Educação Especial, o Ministério da Educação (MEC), por meio de suas orientações publicadas em Brasil (2008, 2011a, b) indica que alunos com deficiência devem receber atendimento especializado denominado como "complementação educacional" e aquelas indicadas com altas habilidades ou superdotação (denominação indicada no documento) "suplementação educacional"4.

A Nota Técnica $\mathrm{n}^{\circ} 62$ (BRASIL, 2011b) ratifica as definições para atendimento suplementar e do Parecer $\mathrm{n}^{\circ} 06$ (BRASIL, 2007, p.03), cuja orientação indica que:

${ }^{4}$ Os termos apontados em legislação não fazem uso de adjetivos para complementação e suplementação, deixando subentendido que se tratam em âmbito educacional. Foram encontrados o uso indiferenciado dos adjetivos "educativo" e "educacional" após o termo suplementação. Nesse trabalho adotou-se o adjetivo "educacional", porém, sugere-se investigar suas diferenças em outra pesquisa. 
"suplementar: compreende o sentido de ampliar, aprofundar ou enriquecer a base nacional comum" e explica que: "fugiria à base nacional comum, strictu sensu, somente as atividades suplementares e as substitutivas".

No que diz respeito à suplementação educacional, Guenther (2012, p.64) destaca:

\begin{abstract}
A suplementação educacional é uma avenida aberta aos alunos dotados, mesmo que não sejam nem ávidos em aprender. De modo geral, ela provê um plano educacional personalizado, compatível com as necessidades, características, qualidades e o modo de ser do aluno.
\end{abstract}

Propõe, todavia, uma intervenção educativa que contemple ampliação de experiência de vida, experiências educativas informais, em uma rede de contatos diversificada com seus pares e pessoas de interesse em comum que possam oferecer sofisticação e novidade em interesses compartilhados..

Nesse cenário, com a escassez de pesquisas e formação de professores para estudantes com potencial elevado, tem-se verificado pouca compreensão de suas necessidades educacionais, tanto por parte do professorado em geral, quanto dos gestores educacionais, além de conceitos diversos e confusos sobre o que vem a ser a referida suplementação educacional. Esse desconhecimento pode ser um dos fatores que mantém esse grupo de alunos sem o devido atendimento.

Sendo assim, buscou-se compreender como se deu o trabalho de suplementação educacional para alunos dotados e talentosos da rede municipal de ensino de São José dos Campos, no interior de São Paulo, entre os anos de 2011 a 2013. Além disso, teve como objetivos específicos: compreender os conceitos de suplementação educacional para alunos dotados e talentosos presentes nos documentos oficiais educacionais e analisar as políticas públicas educacionais da rede de ensino pesquisada pertinentes ao atendimento dos educandos com indicadores de dotação e talento.

\title{
Método
}

A metodologia da pesquisa foi de natureza exploratória com delineamento bibliográfico e documental. A coleta de dados foi realizada na rede municipal de ensino da cidade de São José dos Campos, interior de São Paulo, localizada entre São Paulo e Rio de Janeiro. Os dados para a realização desta pesquisa foram coletados nos 
documentos do Programa Decolar ${ }^{5}$, da Secretaria de Educação do Município, sob a guarda do arquivo central da Secretaria Municipal de Educação.

Os procedimentos para a coleta de dados seguiram os seguintes encaminhamentos:

1. Solicitação à Secretaria Municipal de Educação do município, local da pesquisa, para autorização de levantamento dos documentos junto ao órgão;

2. Levantamento dos dispositivos legais pertinentes ao tema estudado;

3. Levantamento de documentos educacionais na Secretaria Municipal de Educação pesquisada;

4. Levantamento do número de alunos dotados atendidos no município entre 2011 e 2013;

5. Verificação dos registros de procedimentos suplementares educacionais oferecidos aos alunos atendidos do referido sistema de ensino;

6. Coleta de dados documentais no arquivo central e no departamento de planejamento da Secretaria Municipal de Educação.

As informações foram extraídas de relatórios da coordenação, folhas de frequência das atividades, atas de reuniões, registros de voluntários e parceiros, registros de atividades extras, listas de presença, folhas de avaliação, recorte de jornais e documentos oficiais, como Portarias e Deliberações. Além disso, os dados do censo escolar foram coletados no Departamento de Planejamento da Secretaria Municipal de Educação sob a forma de relatório com os números de cada ano.

Para os procedimentos de análise de dados foram seguidos os seguintes caminhos: analisou-se o número de alunos atendidos no período de 2011 a 2013 a partir do Censo Escolar fornecidos pelo departamento de planejamento da Secretaria Municipal de Educação; levantou-se o número de alunos matriculados no período por meio do Censo Escolar/INEP(BRASIL, 2011, 2012, 2013, 2015) para verificar a porcentagem de alunos atendidos nos anos finais do ensino fundamental. Foram analisados o número de escolas atendidas a fim de saber qual a amplitude do programa; as atividades grupais e individuais ofertadas pelo programa, comparando-se a oferta em

5 O Programa Decolar - Desenvolvimento do Potencial e Talento - é um programa de atendimento educacional especializado com espaços de apoio e suplementação educacional ao aluno excepcional, dotado e talentoso da Secretaria Municipal de Educação de São José dos Campos, vinculado ao departamento de educação especial e em corresponsabilidade com as escolas de ensino fundamental da rede municipal (Relatório das Atividades 2013, SÃO JOSE`DOS CAMPOS, 2014a). 
relação ao $1^{\circ}$ e $2^{\circ}$ semestre para analisar a área de interesse dos alunos e se houve atividades extras durante o período.

\section{Resultados}

\section{Programa Decolar: caracterização e funcionamento}

O Programa Decolar iniciou o atendimento em julho de 2007; com base na LDBEN - Lei de Diretrizes e Bases da Educação Nacional -, nº 9.394/96, e na Deliberação 02/03 do Conselho Municipal de Educação (SÃO JOSÉ DOS CAMPOS, 2003), que fixava normas para a educação de alunos que apresentam necessidades educacionais especiais.

Em 2012, o Programa teve sua criação formalizada pela Portaria $n^{0}$ 170/SME/2012, (SÃO JOSÉ DOS CAMPOS, 2012a), publicada no Boletim do Município em 06/07/2012, bem como a atribuição de aula regida pela Portaria $\mathrm{n}^{\mathrm{o}}$ 249/SME/2012, (SÃO JOSÉ DOS CAMPOS, 2012b). No ano seguinte, essa Portaria foi revogada e o atendimento aos alunos dotados e talentosos foi integrado a uma nova Portaria da Educação Especial n ${ }^{0}$ 204/SME/13, publicada no Boletim do Município em 18/10/13, (SÃO JOSÉ DOS CAMPOS, 2013), passando a se chamar Núcleo de Atividades de Altas Habilidades/Dotação, conforme anexo 2.

A Deliberação da Educação Especial, do ano de 2014, foi atualizada conforme as políticas públicas da Educação Especial na Perspectiva da Educação Inclusiva (BRASIL, 2008); sendo promulgada a Deliberação CME nº 02/14 (SÃO JOSÉ DOS CAMPOS, 2014b) a qual vige a Educação Especial no município atualmente. Além do Programa Decolar, a secretaria de educação, também, mantinha paralelamente um convênio com o Instituto Social para Motivar Apoiar e Reconhecer Talentos (Ismart), que oferece bolsas de estudo para alunos dotados e talentosos na área acadêmica.

O Programa Decolar atendeu no período pesquisado - 2011 a 2013 - alunos dotados e talentosos de todos os domínios de capacidade do $6^{\circ}$ ao $9^{\circ}$ ano do ensino fundamental, em 40 escolas, baseado na metodologia CEDET - Caminhos para Desenvolver Potencial e Talento criado pela pesquisadora Zenita Cunha Guenther, em 2011. 
No caso do Programa Decolar, conforme explicitado no Relatório das atividades de $2013^{6}$, pulicado em janeiro de 2014 (SÃO JOSÉ DOS CAMPOS, 2014a), haviam "unidades" nas regiões da cidade (norte, sul, leste e centro), nas quais os alunos participavam de diversas atividades diariamente. Nota-se, porém, que em 2013, essas unidades foram centralizadas no CEDEMP - Centro de Educação Empreendedora, passando a atender os alunos de todas as regiões no sul da cidade.

Nesse Centro reunia-se a equipe multidisciplinar composta por professoras de diversas áreas de formação, como Pedagogia, Letras, Matemática, História, Biologia, etc. e especializadas em educação especial de dotados e talentosos chamadas de "facilitadoras" por essa metodologia. Cada uma delas era responsável por três ou quatro escolas e com cerca de 60 alunos, trabalhando de forma itinerante.

A identificação dos alunos era de responsabilidade das facilitadoras. Inicia-se esse processo com a "observação direta em sala de aula" ${ }^{7}$ nos $3^{\circ}, 4^{\circ}$ e $5^{\circ}$ anos do ensino fundamental. Era realizada pelo professor regente dos anos iniciais, pois, ocorria uma vez por ano no mês de outubro quando o professor já possuía conhecimento suficiente para oferecer dados concretos e seguros sobre os alunos.

Após ter sido realizada a observação direta por duas vezes, em dois anos consecutivos e por professores diferentes, a facilitadora estudava os dados com base na metodologia CEDET, nos quais já eram sinalizados os alunos e os domínios de capacidade por eles expressos. Em seguida, a facilitadora chamava esses alunos para a segunda etapa: a "observação assistida"8.

Nessa segunda etapa, a observação era realizada pela facilitadora, que possuía conhecimento especializado na área de educação de alunos dotados e talentosos. Finalmente, realizava uma análise de todos os dados coletados nas observações, bem como outros dados coletados na escola e com a família, conforme cada caso. O aluno e a família eram convidados a participar do Programa Decolar. O (a) aluno (a) permanecia

${ }^{6}$ Relatório das atividades de 2013, Programa Decolar (2014)

${ }^{7}$ A Observação Direta em Sala de Aula é a primeira fase da coleta de dados para a identificação dos alunos dotados. O professor regente da turma recebe uma folha de itens que abrangem indicadores de dotação e talento e, a partir dela, observa os alunos e anota na folha os dois que se sobressaem naquele grupo de comparação em cada indicador (GUENTHER, 2011)

${ }^{8}$ A Observação Assistida é a segunda fase na qual os alunos sinalizados na observação direta são observados pelas facilitadoras em situações variadas não escolares, em situações de aprendizagem, desempenho, tomada de posição, escolhas, em interação com outros alunos também sinalizados, proporcionando a chance de expressarem os vários domínios de capacidades, momentos a partir dos quais as facilitadoras coletam mais dados a fim de, então, finalizar o processo de identificação (GUENTHER, 2011). 
estudando na escola regular, mas, passava a receber o atendimento educacional especializado.

Em geral, o atendimento acontecia em dois momentos: nos encontros semanais com a facilitadora na escola e nas atividades grupais e individuais. Todas as atividades realizadas eram previamente conversadas com cada aluno, buscando atender seus interesses, necessidades, objetivos e domínios de capacidade, em contraturno. As facilitadoras faziam um trabalho de contato com a escola, realizando interlocução com os educadores dos alunos, apoiadas pelo "assistente interno" que é um educador da escola designado a acompanha-los.

As atividades citadas aconteciam nas unidades do Programa Decolar, nas próprias escolas ou em instituições da comunidade que recebiam os alunos e ofertavam os conteúdos de interesse deles. Em 2011, por exemplo, o Instituto Nacional de Pesquisas Espaciais - INPE ofereceu astronomia, a Faculdade de Tecnologia - FATEC ofereceu informática e, ainda, a Universidade do Vale do Paraíba - UNIVAP ofereceu botânica, borboletário, serpentário e anatomia.

Para a realização dessas atividades, Guenther (2011) aponta como importantes algumas características: ampliar experiência de vida por meio do interesse do aluno e de experiência concreta; tempo: a curto prazo (oito a dez horas de trabalho por semana) a médio prazo (quatro a cinco anos de continuidade) e a longo prazo (continua a se desenvolver na vida adulta); provisão de oportunidades de vivências; inspiração e modelo por meio da convivência com pares compatíveis e pessoas admiráveis.

Além disso, a referida autora também aponta a rede de educação informal e a aprendizagem sedimentada como fatores importantes no processo educativo dos alunos dotados.

Quanto à aprendizagem sedimentada, Guenther (2012) explica que a base de transferência que fundamenta o desenvolvimento do potencial previsto no plano genético está na aprendizagem sedimentada por conexões cerebrais de longa duração. E ela explica, que é preciso gerar oportunidades intencionais de aprendizagem, focadas na vivência e na experiência que o aluno terá a partir dos interesses e necessidades de cada um. Nesse momento, estão incluídos os conteúdos específicos que serão trabalhados com os alunos e que devem possuir as seguintes características: enriquecimento, aprofundamento, sofisticação e novidade (GUENTHER, 2012). 
Todas essas características foram consideradas nas atividades do Programa Decolar no momento de se constituir o plano individual de trabalho de cada aluno (a), a partir do qual foram criadas as atividades grupais e individuais.

O acompanhamento era realizado por uma facilitadora que compartilhava as informações de cada grupo em reunião semanal de equipe. O conteúdo era lecionado por voluntários da comunidade, recrutados pelas facilitadoras, que buscaram as pessoas que poderiam compartilhar conhecimento e experiência de vida com as crianças. As atividades eram divididas em três áreas pedagógicas de acordo com a metodologia CEDET: Comunicação, Organização e Humanidades (Eu e o outro); Ciência, Investigação e Tecnologia (Eu e o mundo) e Criatividade, Habilidades e Expressão (Eu comigo mesmo). Essas áreas abrangem o desenvolvimento pessoal e humano, baseadas em pensamentos humanistas (SÃO JOSÉ DOS CAMPOS, 2014a), conforme explica Guenther (2011, p.157):

\begin{abstract}
nessa maneira de pensar, a educação abraça o compromisso de procurar meios para prover intencionalidade e direção ao projeto educativo visando o desenvolvimento de crianças com alta capacidade e dotação, focalizando o processo não no talento identificado, mas na formação pessoal, segundo as dimensões básicas da personalidade descritas pelo pensamento humanista: self, eu (auto-conceito), interrelações com os outros (conceito do outro), construção de relações aceitáveis com o mundo (visão de mundo) (Destaque da autora citada).
\end{abstract}

Ao final do semestre, as facilitadoras avaliavam cada atividade realizada junto aos grupos, voluntários e alunos, bem como as atividades individuais com cada aluno e da execução do seu plano individual de trabalho. Em todo o processo, o aluno era colocado como protagonista do processo educativo, contando com o apoio das facilitadoras para desenvolver seu plano individual de trabalho.

\title{
Atendimento
}

A partir da compreensão da caracterização e do funcionamento do Programa Decolar, investigou-se o atendimento aos alunos dotados e talentosos nos anos de 2011, 2012 e 2013 dos anos finais do ensino fundamental, ou seja, $6^{\circ} \mathrm{s}, 7^{\circ} \mathrm{s}, 8^{\circ}$ s e $9^{\circ}$ anos. Esse atendimento é compreendido como todo o processo de suplementação educacional explicitado anteriormente o que inclui as atividades na escola, principalmente, os 
encontros semanais com a facilitadora, a elaboração e a execução do plano individual semestral de trabalho, bem como as atividades que aconteceram no período contrário de aula.

Foram investigados os atendimentos das atividades ocorridas em horário contrário de aula regular, visto que elas eram parte da concretização do plano individual de trabalho de cada aluno, embora, não fossem o atendimento na sua totalidade.

Segundo dados do Censo Escolar/INEP e da Secretaria Municipal de Educação de São José dos Campos, no ano de 2011 houve 16.713 matrículas nos anos finais do ensino fundamental e 503 alunos atendidos no Programa Decolar. Esse número de alunos corresponde a 3\% dessa população escolar. Em 2012 ocorreram 16.880 matrículas e 363 atendimentos, correspondendo a 2,2\%. Já em 2013 houve 15.624 matrículas e 318 atendimentos, o que correspondeu a 2,0\%, expostos na Tabela 1.

Tabela 1: Matrículas nos anos finais do ensino fundamental e alunos atendidos no Programa Decolar - 2011-2013.

\begin{tabular}{c|c|c|c}
\hline Ano & Matrículas & Atendidos & Porcentagem \\
\hline $\mathbf{2 0 1 1}$ & 16.713 & 503 & $3,0 \%$ \\
\hline $\mathbf{2 0 1 2}$ & 16.880 & 363 & $2,2 \%$ \\
\hline $\mathbf{2 0 1 3}$ & 15.624 & 318 & $2,0 \%$ \\
\hline Média & - & - & $2,4 \%$ \\
\hline
\end{tabular}

Fonte: Elaboração própria.

Pela distribuição de características humanas, há no mínimo de 3 a 5\% de pessoas dotadas e talentosas em qualquer população (Guenther, 2011, p.26). Com os números acima, pode-se verificar que a rede municipal de ensino de São José dos Campos identificou e atendeu em média 2,4\% dos alunos com essa característica no período estudado, chegando bem próximo do mínimo provável. Além disso, observou-se uma queda contínua no número de alunos atendidos, motivo pelo qual foram investigados os atendimentos ao longo do tempo estudado. Dessa forma, coletou-se o número de alunos dotados e talentosos atendidos desde o início do Programa Decolar em 2007 até o ano de 2015, tendo sido atendidos 89 alunos em 2007, 400 em 2008, 470 em 2009, 586 em 
2010, 503 em 2011, 363 em 2012, 318 em 2013, 257 em 2014 e 197 em 2015. O que constatou a ascensão e queda do atendimento, ilustrado no gráfico 1.

Gráfico 1: Alunos atendidos em São José dos Campos: 2007 a 2015.

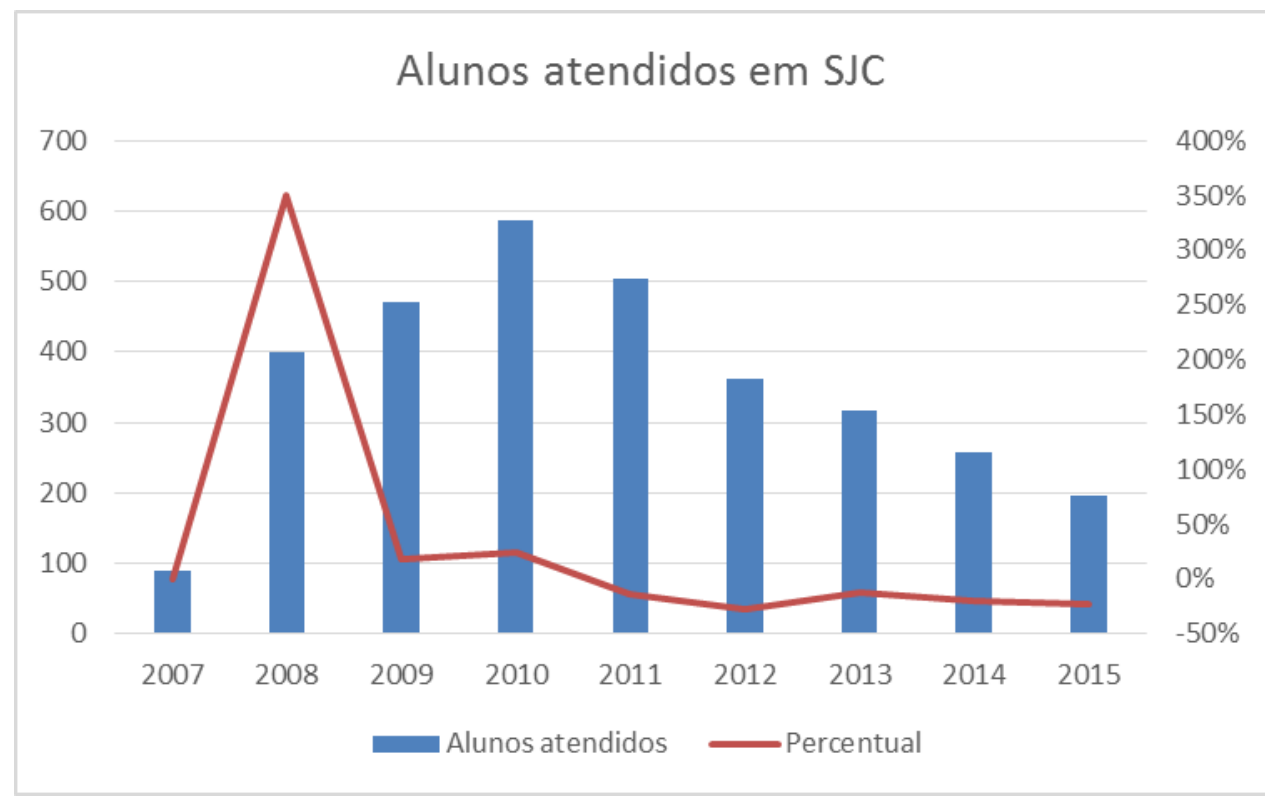

Fonte: Elaboração própria.

Importante citar que os dados oficiais do censo possuem registro dos atendimentos a partir do ano de 2011, sendo que os dados dos anos anteriores foram coletados nos relatórios da coordenação do Programa Decolar. Outra informação relevante, é que no ano de 2013 foram registrados no Censo 359 alunos dotados e talentosos atendidos pela rede municipal, sendo 318 pelo Programa Decolar, 41 pelo Ismart e 19 atendidos em ambos. Essa especificação consta apenas no ano de 2013.

Nos primeiros anos do Programa Decolar, entre 2007 e 2010, observou-se um aumento contínuo do número de alunos atendidos. Uma tendência esperada para um trabalho com três anos de existência. Em 2008, o crescimento foi de 349\%, em 2009 de $18 \%$, em 2010 de $25 \%$.

Infere-se, em 2011, uma tendência de queda contínua intercalada com quedas menores e maiores. Em 2011, a queda foi de 14\%, em 2012 de 28\% e em 2013 foi de 12\%. Em 2014, a queda foi de $19 \%$ e em 2015 de 23\%. Os dados não demonstraram o motivo do início da queda em 2011, para o qual, sugere-se uma nova pesquisa para essa análise. 
Entretanto, os dados apresentaram mudanças no atendimento em 2013. Em 18/10/13, foi publicada a Portaria da Educação Especial no 204/SME/13 (SÃO JOSÉ DOS CAMPOS, 2013), momento em que o programa deixou de existir formalmente e passou a se chamar Núcleo de Atividades de Altas Habilidades/Dotação.

A queda no número de alunos atendidos manteve-se até o último censo escolar publicado em 2015. Com relação à queda e à mudança na forma do atendimento, podese inferir que não houve novas identificações e atendimentos a partir de 2014. Sendo que, o Censo Escolar 2015 registrou 14.761 matrículas nos anos finais do ensino fundamental na rede municipal e poderia estimar a existência entre 442 e 738 de alunos, número bem maior que os 197 registrados em 2015.

Além do número de alunos atendidos, o Relatório das atividades de 2013 (SÃO JOSÉ DOS CAMPOS, 2014a) registrou também o número de escolas atendidas ao longo de sua existência. O atendimento iniciou com 17 escolas em 2007, ampliou para 38 escolas em 2008, para 39 em 2009 e 2010, caiu para 38 em 2011, depois subiu para 40 em 2012 e 2013.

Esse dado demonstra a grande amplitude do atendimento realizado em todas as regiões da cidade.

\section{Atividades suplementares}

Ao longo do ano de 2011, o Programa Decolar ofertou 61 atividades grupais no total, sendo 27 no primeiro semestre e 34 no segundo. Em 2012 ofertou 69 atividades grupais com 33 no primeiro semestre e 36 no segundo. Essas atividades foram distribuídas nas três áreas de estimulação já mencionadas. Já em 2013, o Programa realizou 57 atividades grupais, tendo sido 26 no primeiro e 31 no segundo semestre, bem como 844 atividades individuais, ocorrendo 393 no primeiro semestre e 451 no segundo. A tabela 2 demonstra esses resultados.

Tabela 2 - Atividades grupais 2011-2012-2013.

\begin{tabular}{c|c|c|c}
\hline \multicolumn{4}{c}{ Atividades grupais 2011 } \\
\hline Áreas & $1^{\circ}$ Semestre & $2^{\circ}$ Semestre & Resultado \\
\hline $\begin{array}{c}\text { Ciências, Investigação } \\
\text { e Tecnologia }\end{array}$ & 14 & 18 & 32 \\
\hline $\begin{array}{c}\text { Criatividade, } \\
\text { Habilidades e Expressão }\end{array}$ & 3 & 5 & 21 \\
\hline $\begin{array}{c}\text { Comunicação, } \\
\text { Organização e Humanidades }\end{array}$ & 10 & 11 & 8 \\
\hline
\end{tabular}




\begin{tabular}{c|c|c|c} 
Total & 27 & 34 & $\mathbf{6 1}$ \\
\hline \multicolumn{3}{c}{ Atividades grupais 2012 } \\
\hline Áreas & $1^{\circ}$ Semestre & $2^{\circ}$ Semestre & Resultado \\
\hline $\begin{array}{c}\text { Ciências, Investigação } \\
\text { e Tecnologia }\end{array}$ & 13 & 13 & 26 \\
\hline $\begin{array}{c}\text { Criatividade, } \\
\text { Habilidades e Expressão }\end{array}$ & 5 & 4 & 9 \\
\hline $\begin{array}{c}\text { Comunicação, } \\
\text { Organização e Humanidades }\end{array}$ & 15 & 19 & 34 \\
\hline Total & 33 & 36 & $\mathbf{6 9}$ \\
\hline
\end{tabular}

Atividades 2013

\begin{tabular}{|c|c|c|c|c|c|}
\hline & \multicolumn{2}{|c|}{$1^{\circ}$ Semestre } & \multicolumn{2}{|c|}{$2^{\circ}$ Semestre } & \multirow[t]{2}{*}{ Resultado } \\
\hline Áreas & rupais $^{\mathrm{G}}$ & $\begin{array}{l}\text { Indiv } \\
\text { iduais } \\
\end{array}$ & $\begin{array}{l}\text { Grup } \\
\text { ais }\end{array}$ & $\begin{array}{r}\mathrm{I} \\
\text { ndividuais } \\
\end{array}$ & \\
\hline $\begin{array}{l}\text { Ciências, Investigação } \\
\text { e Tecnologia }\end{array}$ & $2 \quad 1$ & 149 & 14 & $85^{1}$ & 360 \\
\hline $\begin{array}{c}\text { Criatividade, } \\
\text { Habilidades e Expressão }\end{array}$ & 4 & 175 & 6 & 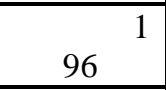 & 381 \\
\hline $\begin{array}{c}\text { Comunicação, } \\
\text { Organização e Humanidades }\end{array}$ & 1 & 69 & 11 & 7 & 160 \\
\hline Total & $6^{2}$ & 393 & 31 & 514 & 901 \\
\hline
\end{tabular}

Fonte: Elaboração própria.

Quanto às atividades grupais, em 2011 ocorreram 27 ofertadas no primeiro semestre e 34 no segundo. Em 2012, foram 33 no primeiro semestre e 36 no segundo. Já em 2013 aconteceram 26 atividades grupais no primeiro semestre e 31 no segundo, conforme ilustra o gráfico 2 .

Gráfico 2: Atividades grupais: 2011 a 2013

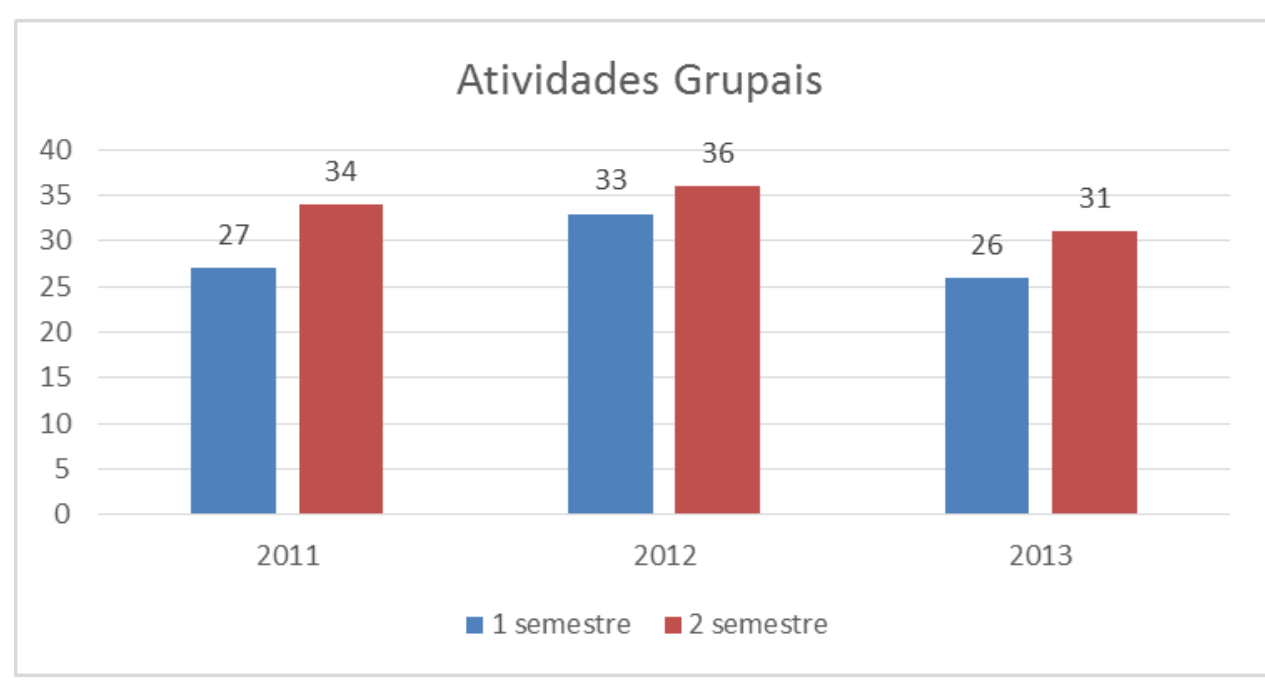

Fonte: Elaboração própria. 
Notou-se que em todos os anos houve mais atividades grupais no segundo semestre do que no primeiro. Ao calcular a média geral de alunos nos grupos em cada semestre de cada ano, obteve-se o seguinte dado: em 2011 existiam 18 alunos por grupo no primeiro semestre e 14 no segundo, em 2012 haviam 11 alunos por grupo no primeiro semestre e 10 no segundo e em 2013 haviam 12 alunos por grupo no segundo semestre e 10 no segundo. Com base nesses números, poder-se-ia inferir que no segundo semestre de cada ano ocorreu uma diversidade maior de interesses, talvez, como consequência de um aprofundamento do semestre anterior. Essa hipótese pode ser constatada por meio de nova pesquisa, que aprofunde o tema da suplementação educacional.

Quanto à tendência de aumento nas atividades grupais nos segundos semestres dos anos de 2011 a 2013, houve área de estimulação que se sobressaiu em quantidade. A área de Ciências, Investigação e Tecnologia (CITEC), em 2011, teve um aumento de 29\%, de 0\% em 2012 e de 17\% em 2013 no segundo semestre em relação ao semestre anterior. As áreas: Criatividade, Habilidades e Expressão (CRHEX) tiveram aumento de 67\%, em 2011, queda de 20\% em 2012 e um aumento de 50\% em 2013. Por fim, a área de Comunicação, Organização e Humanidades $(\mathrm{COH})$ teve um aumento de $10 \%$ em 2011, de 27\% em 2012 e de 10\% em 2013, no segundo semestre em relação ao semestre anterior. Observa-se essa variação das atividades por área no gráfico 3.

Gráfico 3: Variação de atividades por área no 2o semestre: 2011 a 2013

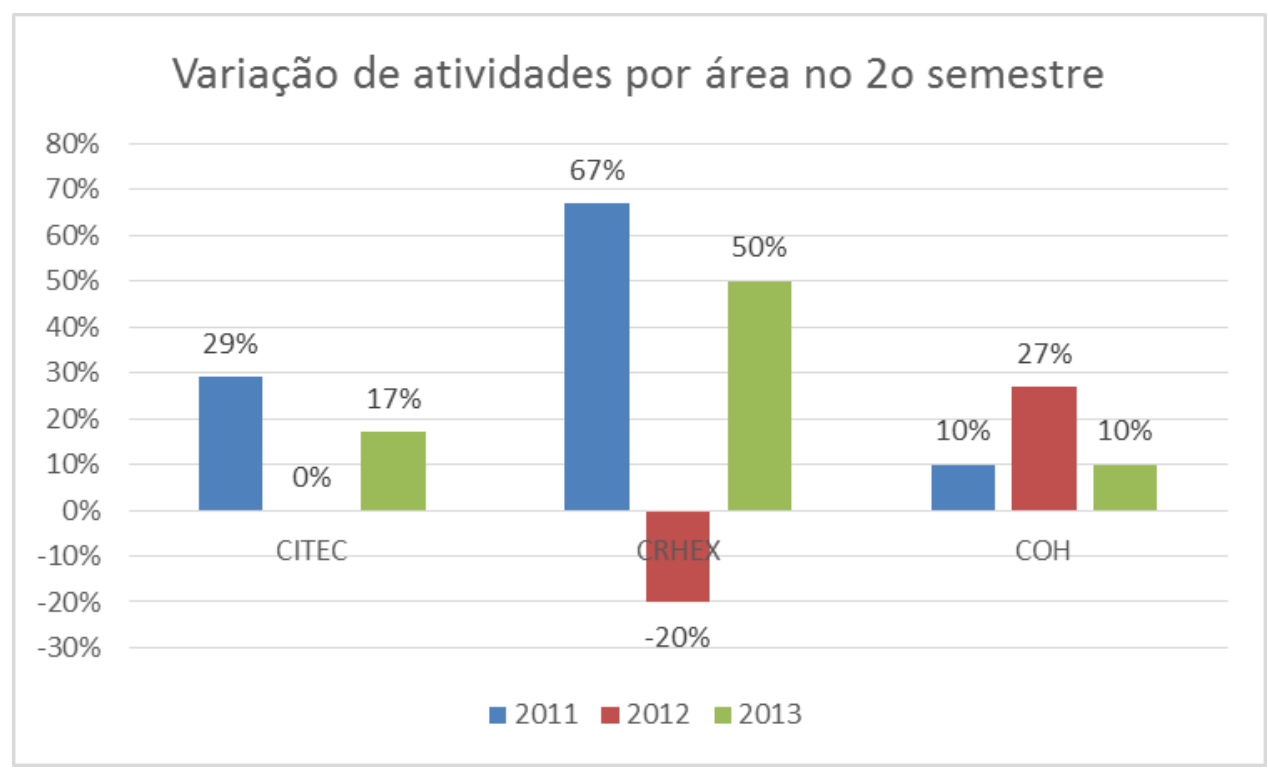

Fonte: Elaboração própria. 
Percebeu-se, que em 2011 todas as áreas tiveram aumento no número de atividades grupais no segundo semestre em relação ao semestre anterior, sendo que a área CRHEX houve o maior aumento. No ano seguinte, cada área se comportou de forma diferente: CITEC manteve o mesmo número, CRHEX teve queda e $\mathrm{COH}$ teve aumento no número de atividades grupais e, por fim, em 2013 todas tiveram aumento, tendo a CRHEX tido a maior incidência novamente.

A variação entre as atividades de um semestre a outro e, ao longo dos anos, demonstrou que os interesses, necessidades e objetivos apareceram de forma diferente nos planos individuais de cada semestre, sugerindo que os planos do aluno foram efetivamente individualizados e reavaliados no final, bem como a possibilidade de aprofundamento no segundo semestre pode ser a razão para o aumento no número de atividades. Dessa forma, não foi encontrada tendência de aumento significativo em nenhuma área.

Comparou-se, também, o número de alunos atendidos com o total de atividades grupais realizadas por ano. A partir disso, percebeu-se uma queda de $28 \%$ no número de alunos atendidos em 2012 com relação a 2011, mas um aumento de 12\% nas atividades grupais. No ano de 2013, houve uma diminuição de $12 \%$ no número de alunos atendidos com relação ao ano anterior, tendo sido acompanhada por uma queda de $21 \%$ no número de atividades grupais. Pode-se inferir que o número de atividades não teve relação direta com o número de alunos, ou seja, não houve um número fixo de atividades por aluno, apesar, que o número de atendidos influenciou a quantidade de atividades existentes.

Os dados obtidos não mostraram a razão da queda no número de alunos em 2012, nem do aumento no número de atividades grupais. Em 2013, porém, sabe-se que houve mudanças no atendimento, como por exemplo, a mudança física das quatro unidades espalhadas nas regiões da cidade, centralizadas na região sul. A causa para a diminuição das atividades grupais pode estar relacionada à dificuldade de acesso, no entanto, seria necessário aprofundar essa questão em outro estudo para verificar a razão da diminuição.

Com relação às áreas, observou-se que há uma prevalência no número de atividades na área de estimulação da CITEC. Essa área teve um total de 84 atividades grupais nos três anos, enquanto que a área de COH teve 76 e a CRHEX teve 27, como ilustra gráfico 4 . 
Gráfico 4: Atividades grupais por área

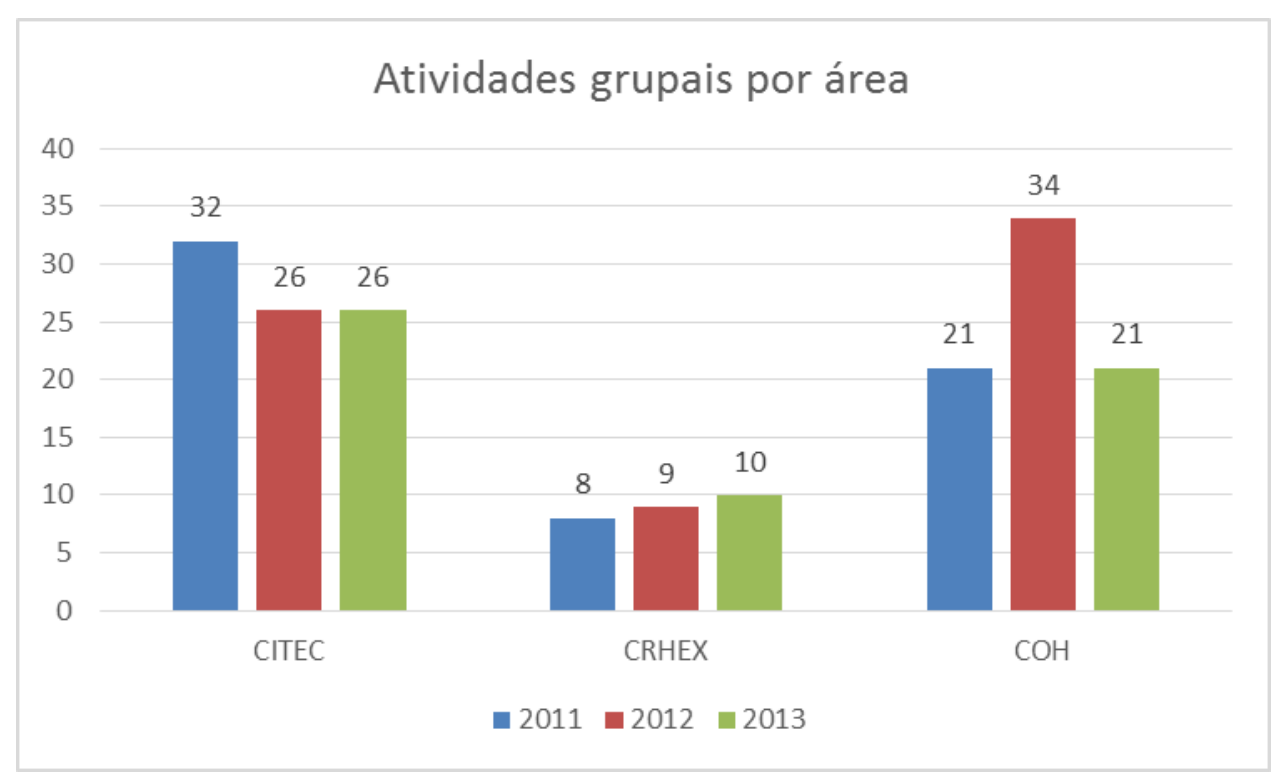

Fonte: Elaboração própria.

Pode-se observar que a CITEC teve maior número de atividades em 2011 e em 2013, seguida pela $\mathrm{COH}$ que foi o segundo maior número de atividades grupais em 2011 e 2013 e prevaleceu em 2012 e, por fim, a área de CRHEX que obteve menor incidência de atividades grupais em todos os anos. Pode-se concluir o foco na área da CITEC possivelmente teve influência do contexto social; visto que a cidade de São José dos Campos é considerada um polo industrial e tecnológico.

Quanto às atividades individuais, foi possível coletar informações apenas do ano de 2013. Nesse ano houve um total de 844 atividades individuais nas três áreas de estimulação tendo sido 393 no primeiro semestre e 451 no segundo, de acordo com o apresentado no gráfico 5 . 
Gráfico 5: Atividades individuais 2013

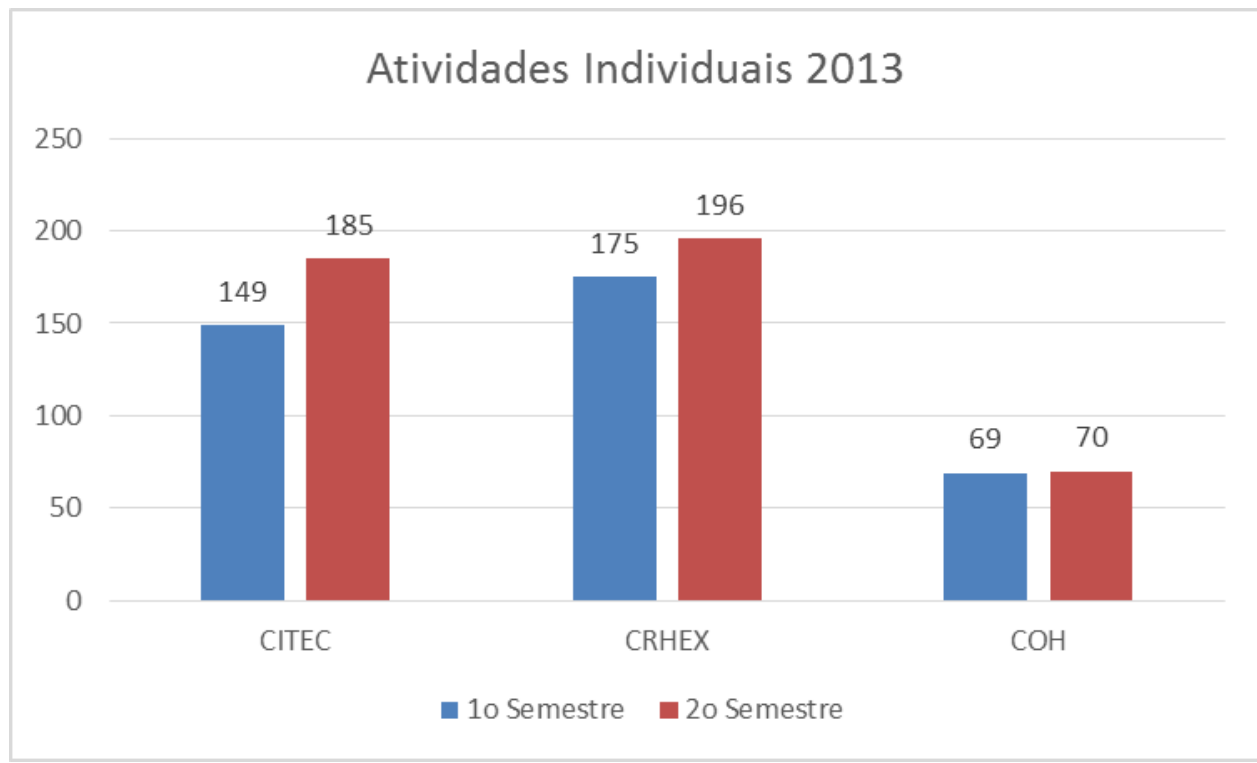

Fonte: Elaboração própria.

$\mathrm{Na}$ área de CITEC houve 149 atividades individuais no primeiro semestre e 185 no segundo. Na CRHEX houve 175 atividades individuais no primeiro semestre e 196 no segundo. Por fim, na $\mathrm{COH}$ ocorreram 69 atividades individuais no primeiro semestre e 70 no segundo. Assim, como no caso das atividades grupais, pode-se observar uma tendência de aumento de atividades no segundo semestre.

Ainda, uma incidência maior de atividades individuais na área de CRHEX e um número menor na área de $\mathrm{COH}$. Se trazermos para essa análise os dados anteriores, a área CRHEX é a que apresenta o menor número de atividades grupais em todos os anos. Segundo Guenther (2011), cada área concentra um objetivo na formação pessoal dos alunos.

De qualquer forma, ao comparar o número de atividades grupais e individuais no ano de 2013, percebeu-se uma grande diferença na quantidade de atividades dessas categorias. No ano em questão houve um total de 57 atividades grupais, tendo sido 26 no primeiro semestre e 31 no segundo e 844 atividades individuais, com 393 no primeiro semestre e 451 no segundo.

Não há dados sobre as atividades individuais de 2011 e 2012, por isso não se sabe se esse fato ocorreu também nesses anos. Entretanto, foi possível relacionar as atividades individuais com o foco no plano individual de cada aluno, ponto chave de todo o trabalho dentro da metodologia CEDET, bem como, com objetivos do 
atendimento educacional especializado, conforme o artigo $3^{\circ}$ do Decreto 7.611 (BRASIL, 2011a, p.02).

Art. 3o São objetivos do atendimento educacional especializado: I - prover condições de acesso, participação e aprendizagem no ensino regular e garantir serviços de apoio especializados de acordo com as necessidades individuais dos estudantes (Grifo nosso).

Dessa forma, é possível dizer que a proporção das atividades grupais e individuais reflete as necessidades de cada aluno estabelecido no plano individual, buscando um aperfeiçoamento dos objetivos individuais, sem deixar de promover a convivência entre pares nos grupos semanais e nas outras atividades, como o "Encontro Geral", as palestras e excursões, bem como atividades na sala de aula regular.

Além das atividades grupais e individuais semanais, levantaram-se dados de outras atividades ocorridas ao longo do período estudado, sendo elas: palestras, excursões e encontros gerais ${ }^{9}$.

Em 2011 aconteceu uma visita ao museu natural de Taubaté. Em 2012, ocorreram: a) Excursão História \& Arte - Teatro Municipal/Biblioteca Municipal de SP; Memorial da América Latina - exposição Guerra e Paz - Portinari; b) Viagens e aventuras - Cidade de Paraibuna; - Cidade de Cunha; e - Cidade de São Paulo (Estação da Luz, Centro antigo e Avenida Paulista); c) Competição- Projeto Baja/SAE Brasil ${ }^{10}{ }_{-}$ ECPA - Esporte Clube Piracicabano de Automobilismo, Piracicaba, SP; d) Visitas, palestras e encontro - Museu de Oceanografia da Universidade de São Paulo - USP; Palestra Haiti - Decolar; Palestra sobre Intercâmbio de Jovens - Rotary; e Encontro Geral 2012. Por fim, em 2013, aconteceram palestras e encontros: - Palestra com o Cientista Nilton Rennó - bate papo sobre seu trabalho com ciências planetárias e pesquisas com o robô Curiosity em Marte - National Aeronautics and Space Administration - NASA e sobre sua trajetória estudantil e profissional; Palestra: Conhecendo Engenharias Poli-USP; e Encontro Geral 2013.

${ }^{9}$ Um Encontro Geral reúne cerca de 100 crianças de várias escolas, dentro de uma faixa etária e escolar. São momentos para explorar ângulos e temas transversais de interesse amplo, próprios de um momento, uma faixa etária, um meio cultural, ou tratam de assuntos gerais abrangentes. É também uma situação de novidade para o aluno, uma das poucas vezes, no trabalho do CEDET em que ele é posto frente a frente com a tarefa de fazer escolha entre opções oferecidas. (Guenther, 2011, p.101)

10 O programa Baja SAE BRASIL é um desafio lançado aos estudantes de Engenharia que oferece a chance de aplicar na prática os conhecimentos adquiridos em sala de aula, visando incrementar sua preparação para o mercado de trabalho. Ao participar do programa Baja SAE, o aluno se envolve com um caso real de desenvolvimento de um veículo off road, desde sua concepção, projeto detalhado, construção e testes. (http://portal.saebrasil.org.br/programas-estudantis/baja-sae-brasil 
Ainda, em 2011, aconteceu uma excursão. Em 2012, ocorreram cinco excursões e em 2013 não houve nenhuma. Também, não houve nenhuma palestra em 2011, entretanto, houve duas em 2012 e 2013 e o mesmo aconteceu em relação ao Encontro Geral, conforme pode ser observado no gráfico 6.

Gráfico 6: Outras atividades: 2011 a 2013

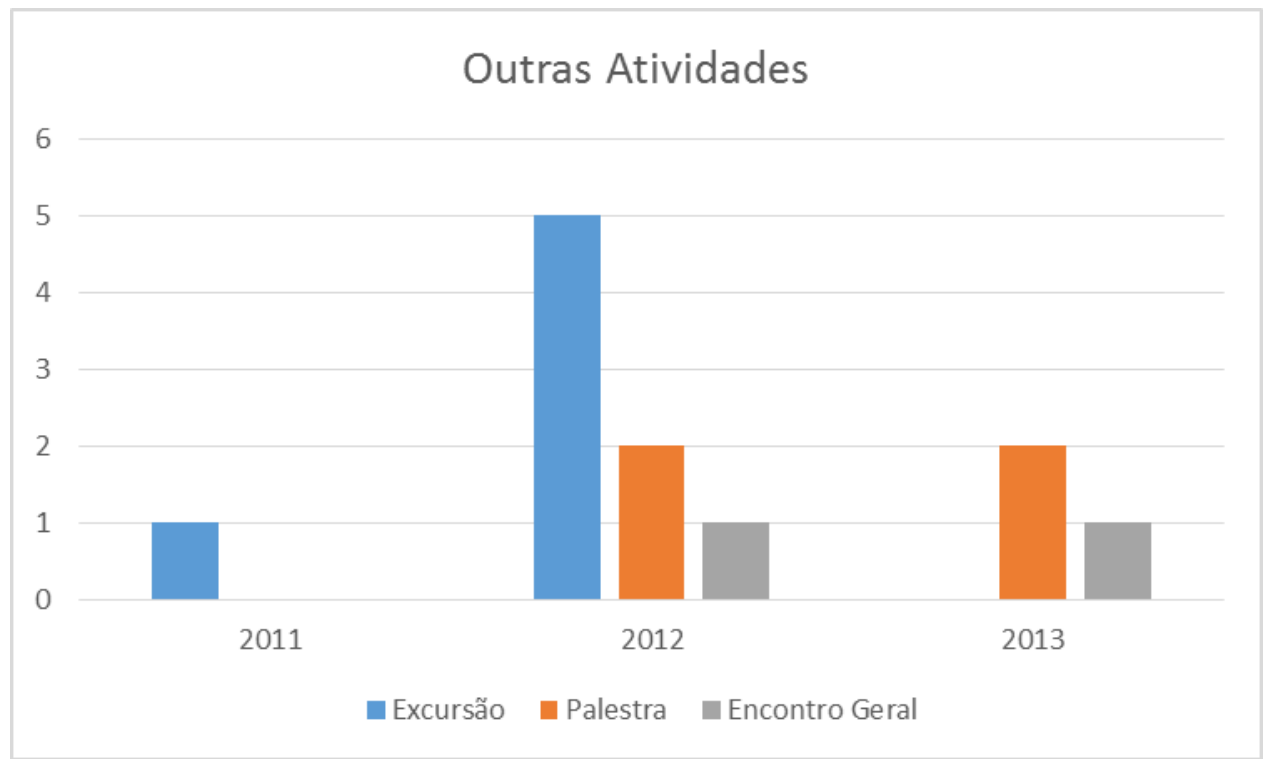

Fonte: Elaboração própria.

\section{Considerações finais}

Pode-se concluir, com esse estudo, que o Programa Decolar atendeu os alunos da rede municipal de ensino de São José dos Campos de 2007 a 2013 e que o atendimento aos alunos dotados e talentosos foi continuado, muito embora em queda, pelo Núcleo de Atividades de Altas Habilidades/Dotação até 2015, período máximo de existência de dados disponíveis.

Observou-se uma diminuição no número de alunos atendidos a partir de 2011, mas, não houve o mesmo decréscimo na oferta de atividades, nem no número de escolas atendidas. Esse dado demonstra uma dificuldade de acesso dos alunos dotados ao atendimento educacional especializado, entretanto, necessita de novos estudos para clarear a causa.

Os resultados demonstraram, também, que o Programa Decolar teve grande amplitude no atendimento no município, tendo ocorrido nas 40 escolas de ensino 
fundamental em todas as regiões da cidade, bem como grande inserção da comunidade e das instituições como parceiras.

Ao observarmos o atendimento no Programa Decolar, foi possível perceber que ele atendeu às políticas públicas educacionais, pois, seu trabalho ocorreu de forma inclusiva, mantendo os alunos na sala de aula regular ao mesmo tempo que, receberam o atendimento educacional especializado nas unidades do programa, que nada mais eram do que os centros de atendimento educacional especializado. Além disso, cada aluno tinha um plano individual de trabalho de acordo com suas necessidades, tendo participado de atividades suplementares individuais e grupais, favorecendo o convívio entre pares, bem como outras atividades extras, possibilitando ampliação da experiência de vida.

Por fim, embora houvesse alguns dados conclusivos, mostrando a relevância da suplementação educacional para alunos dotados e talentosos, não se pretendeu esgotar o tema neste estudo, ao contrário, acredita-se que há a necessidade de pesquisas futuras que objetivem uma melhor compreensão sobre o tema, a fim de que possa, efetivamente, integrar-se como prática em todas as escolas do país.

AGRADECIMENTOS: Agradecemos o apoio, em forma de bolsa PIBIC, do Conselho Nacional de Desenvolvimento Científico e Tecnológico - CNPq.

\section{Referências}

BRASIL. Lei no 9394, de 20 de dezembro de 1996. Estabelece as Diretrizes e Bases da Educação Nacional. Diário Oficial da República Federativa do Brasil. Brasília, DF, n.248, 23 dez. 1996. Seção 1, p.27834-2841 Disponível em: < http://www.planalto.gov.br/ccivil_03/leis/L9394.htm>. Acesso em: 05 abr. 2015.

Ministério da Educação. Secretaria de Educação Especial. Conselho Nacional de Educação. Câmara de Educação Básica. Solicita parecer sobre definição do atendimento educacional especializado para alunos com necessidades educacionais especiais, como parte diversificada do currículo. Parecer CNE/CEB No 06/2007. Brasília, DF, 01.02.2007, 8p. Disponível em:< http://portal.mec.gov.br/cne/arquivos/pdf/pceb006_07.pdf>. Acesso em: 27 mai.2016

Ministério da Educação. Secretaria de Educação Especial. Política Nacional de Educação Especial na Perspectiva da Educação Inclusiva. Brasília: MEC/SEESP, 2008. Disponível em:

http://portal.mec.gov.br/index.php?option=com_docman\&view=download\&alias=1669 0-politica-nacional-de-educacao-especial-na-perspectiva-da-educacao-inclusiva05122014\&Itemid=30192. Acesso em: 18 jun. 2016. 
Decreto $n^{\circ} 7.611$, de 17 de novembro 2011. Dispõe sobre a educação especial, o atendimento educacional especializado e dá outras providências. Diário Oficial da República Federativa do Brasil. Brasília, DF, n.221-A, 18 de novembro de 2011a. Seção 1 - Edição Extra, p.5-6. Disponível em:< http://www.planalto.gov.br/ccivil_03/_ato2011-2014/2011/decreto/d7611.htm>. Acesso em: 27 mar. 2016

. Ministério da Educação. Secretaria de Educação Continuada, Alfabetização, Diversidade e Inclusão. Diretoria de Políticas de Educação Especial. Orientações aos sistemas de ensino sobre o Decreto $n^{\circ} 7.611,2011$. Nota Técnica $\mathbf{n}^{\mathbf{0} 62}$.

2011/MEC/SECADI/DPEE. Brasília, DF, 08 de dezembro de 2011b, 4p. Disponível em: 〈http://www.crianca.mppr.mp.br/arquivos/File/download/nota_tecnica_62.pdf >. Acesso em: 09 abr. 2015.

GAGNÉ, F. Construção da Dotação em Talentos: Desenvolvimento de talentos de acordo com o modelo DMGT, (2005). In: GUENTHER, Z. C. Coleção Debutante, Lavras, MG, 2008, v.I, p.33-38.

GAGNÉ, F. Building gifts into talents.Talent development according to the DMGT.Veröffentlicht in: news\&science. Begabtenförderung und Begabungsforschung.özbf, Nr. 19/Ausgabe 2, 2008, S. 27-30.

GAGNÉ, F; GUENTHER, Z. C. Desenvolvendo talentos: Modelo Diferenciado de Dotação e Talento - DMGT 2.0. In MOREIRA, L. C.; STOLTZ, T. (Coords) Altas habilidades/superdotação, talento, dotação e educação. Curitiba: Editora Juruá, 2012.

GUENTHER, Z. C. Caminhos para desenvolver potencial e talento. Lavras: Ed. UFLA, 2011.

GUENTHER, Z. C. Crianças dotadas e talentosas... não as deixem esperar mais! Rio de Janeiro, LTC, 2012.

INSTITUTO NACIONAL DE ESTUDOS E PESQUISAS EDUCACIONAIS ANÍSIO TEIXEIRA. INEP. Censo Escolar 2011. Disponível em:<http://portal.inep.gov.br/basica-censo>. Acesso em: 19 jul. 2016

Censo Escolar 2012. Disponível em:<http://portal.inep.gov.br/basica-censo $>$. Acesso em: 19 jul. 2016

Censo Escolar 2013. Disponível em: $<$ http://portal.inep.gov.br/basica-censo $>$. Acesso em: 19 jul. 2016

Censo Escolar 2015. Disponível em:<http://portal.inep.gov.br/basica-censo>. Acesso em: 19 jul. 2016

SÃO JOSÉ DOS CAMPOS. Conselho Municipal de Educação. Deliberação CME $02 / 03$. Fixa normas para a educação de alunos que apresentam necessidades educacionais especiais na educação infantil e no ensino fundamental do sistema 
municipal de ensino. Boletim do Município. São José dos Campos, SP, n.1599, 13/02/2004, p.17-18

Secretaria Municipal de Educação. Portaria 170/SME/12.Institui o Programa Decolar, na modalidade de Educação Especial, para atender os alunos bem dotados e talentosos matriculados nas unidades escolares de Ensino Fundamental da Rede de Ensino Municipal de São José dos Campos. Boletim do Município. São José dos Campos, SP, n.2.074, 06/07/2012a, p.34

Secretaria Municipal de Educação. Portaria 249/SME/12. Dispõe sobre o processo de atribuição de aulas para o Programa Decolar aos professores efetivos da Rede Municipal de Ensino. Boletim do Município. São José dos Campos, SP, n.2.086, 21/09/2012b, p.18

Secretaria Municipal de Educação. Portaria 204/SME/13. Dispõe sobre o processo de atribuição de aulas da Educação Especial, aos professores efetivos da REM. Boletim do Município. São José dos Campos, SP, n.2.154, 18/10/2013, p.30

. Secretaria Municipal de Educação. Departamento de Educação Básica. Coordenadoria de Educação Especial. Programa Decolar - Desenvolvimento do Talento. Relatório das atividades de 2013. São José dos Campos, SP, jan.2014a, 61p.

Conselho Municipal de Educação. Deliberação CME 02/014. Dispõe sobre a oferta da modalidade Educação Especial, na perspectiva da Educação Inclusiva, nas escolas do Sistema Municipal de Ensino de São José dos Campos. Boletim do Município. São José dos Campos, SP, n.2.206, 22/08/2014b, p.50-51

\section{Como citar este artigo}

OLIVEIRA, Luciane Mirella de Souza; RANGNI, Rosemeire de Araújo. Suplementação educacional para alunos dotados e talentosos do programa decolar. Revista on line de Política e Gestão Educacional, Araraquara, v.20, n.03, p. 688-709, 2016. Disponível em: <http://dx.doi.org/10.22633/rpge.v20.n3.9764>. ISSN: 15199029.

Submetido em: julho/2016

Aprovado em: setemro/2016 